\title{
Environmental magnetic record of the fluvial sediments from the Tianzhu borehole in Beijing for the last $800 \mathrm{ka}$
}

\author{
Linfeng Shi ${ }^{1,2,3}$, Zhenyu Yang ${ }^{4,5}$, Liandi Zheng ${ }^{4}$, Sanman Jia $^{6}$, Yabo Tong ${ }^{5}$, Shuqin Zhang ${ }^{7}$, Daoyi Xu ${ }^{8}$, and Gaoxuan Guo ${ }^{6}$ \\ ${ }^{1}$ Research and Development Center of Saline Lakes and Epithermal Deposits, Chinese Academy of Geological Science, Beijing, 100037, China \\ ${ }^{2}$ Key Open Laboratory of Saline Lake Resources and Environment, Chinese Academy of Geological Science, Beijing, 100037, China \\ ${ }^{3}$ Institute of Mineral Resources, Chinese Academy of Geological Science, Beijing, 100037, China \\ ${ }^{4}$ Department of Earth Science, Nanjing University, Nanjing, 200093, China \\ ${ }^{5}$ Key Laboratory of Paleomagnetism, Institute of Geomechanics, Chinese Academy of Geological Science, Beijing, 100081, China \\ ${ }^{6}$ Hydrogeology and Engineering Geology Team of Beijing, Beijing, 100037, China \\ ${ }^{7}$ Research Center of paleontology and stratigraphy, Jilin University, Changchun, 130061, China \\ ${ }^{8}$ Institute of Geology, Seismological Bureau of China, Beijing, 100081, China
}

(Received April 9, 2010; Revised July 4, 2010; Accepted July 27, 2010; Online published October 28, 2010)

\begin{abstract}
A high-resolution environmental magnetic investigation has been carried out on a 186.3-m-thick sequence of fluvial sediments from the Tianzhu borehole in the Beijing Plain. Magnetic stratigraphic analysis revealed that the sediment sequence spans the last $800 \mathrm{ka}$ without significant hiatuses. Comparison of the magnetic susceptibility $(k)$ with pollen records suggests that the magnetic susceptibility serves as a good proxy for climate changes. The high $k$ values of the sediments reflect warm climate conditions, and the low $k$ values match cold periods. Magnetic susceptibility records correlate well with the ODP 677 oxygen isotope proxy, with high/low $k$ values corresponding to the interglacial/glacial stages, implying a climate alternation of glacial-interglacial cycles in the Beijing Plain. The lithologic analysis of the Tianzhu borehole cores suggests that climate change was the primary factor in controlling the fluvial sedimentary cycles in the studied area. A fluvial sedimentary model in which precipitation affected the fluvial sediment by controlling the discharge and transport capacity of rivers in different stages may be applied to our research. The rock magnetic records of the Tianzhu fluvial sequence display two extreme events at 750-720 ka and 270-250 ka, respectively, which are regarded as a two-period cycle of aridification and cooling in the Asian interior. The extreme event at 750-720 ka likely resulted from the fast uplift of the Himalayan-Tibetan Plateau and the expansion of Arctic ice-sheet.
\end{abstract}

Key words: Tianzhu borehole, Beijing Plain, magnetic susceptibility, sedimentary model, extreme events.

\section{Introduction}

The initial desertification of the Asian interior is considered to be one of the most prominent climate changes that occurred in the northern hemisphere during the Cenozoic era (Ruddiman and Kutzbach, 1989; Manabe and Broccoli, 1990; Ramstein et al., 1997; An et al., 2001). The results of a magnetostratigraphic survey of the Miocene loess/paleosol sequences in the western Loess Plateau suggest that the onset of desertification in the Asian interior began at least $22 \mathrm{Myr}$ ago (Guo et al., 2002). Uplift of the Tibetan Plateau (Ruddiman and Kutzbach, 1989; Manabe and Broccoli, 1990; An et al., 2001) and changes in landsea distribution (Ramstein et al., 1997) have been proposed as driving forces of the long-term deterioration in the Cenozoic climate. Concomitant with the appearance (Jansen and Sjoholm, 1991) and development of the northern hemispheric ice-sheets (Shackleton and Pisias, 1985; Shackleton et al., 1990, 1995), cooler high-latitude oceans would have provided less moisture to the continental inte-

Copyright (c) The Society of Geomagnetism and Earth, Planetary and Space Sciences (SGEPSS); The Seismological Society of Japan; The Volcanological Society of Japan; The Geodetic Society of Japan; The Japanese Society for Planetary Sciences; TERRAPUB.

doi:10.5047/eps.2010.07.015 rior, which may have also promoted the transition to a much colder and drier Asian interior (Guo et al., 2002, 2004; Ding et al., 2005; Deng et al., 2006). The occurrence of deserts in northern China and the subsequent development of the Loess Plateau are thought to be closely associated with the aridification and cooling of the Asian interior. Therefore, desert loess is a particularly valuable indicator of aridification and cooling evolution in Asia (Kalm et al., 1996; Gu et al., 1999; Sun and Liu, 2000; Chen et al., 2001; Guo et al., 2004; Ding et al., 2005; Deng et al., 2006).

Research on the development of Asian aridification and cooling has focused on the Loess/paleosol sections as these are considered to be classical, continuous continental sequences (Ding et al., 2005; Deng et al., 2006). In contrast, fluvial sediment, also a typical continental sequence characterized by a long-term duration and high resolution, has been little used by the paleoclimate community to date due to its complexity and possible discontinuity. However, cyclic fluvial sediment in alluvial plains in an ongoing subsidence basin can be almost fully preserved, thereby possibly providing valuable paleoclimate proxies (Nádor et al., 2003). The Beijing Plain belongs to the intersection of the wet and semi-dry areas in Eastern Asia. As such, this region was sensitive to Asian aridification and cooling and the ex- 


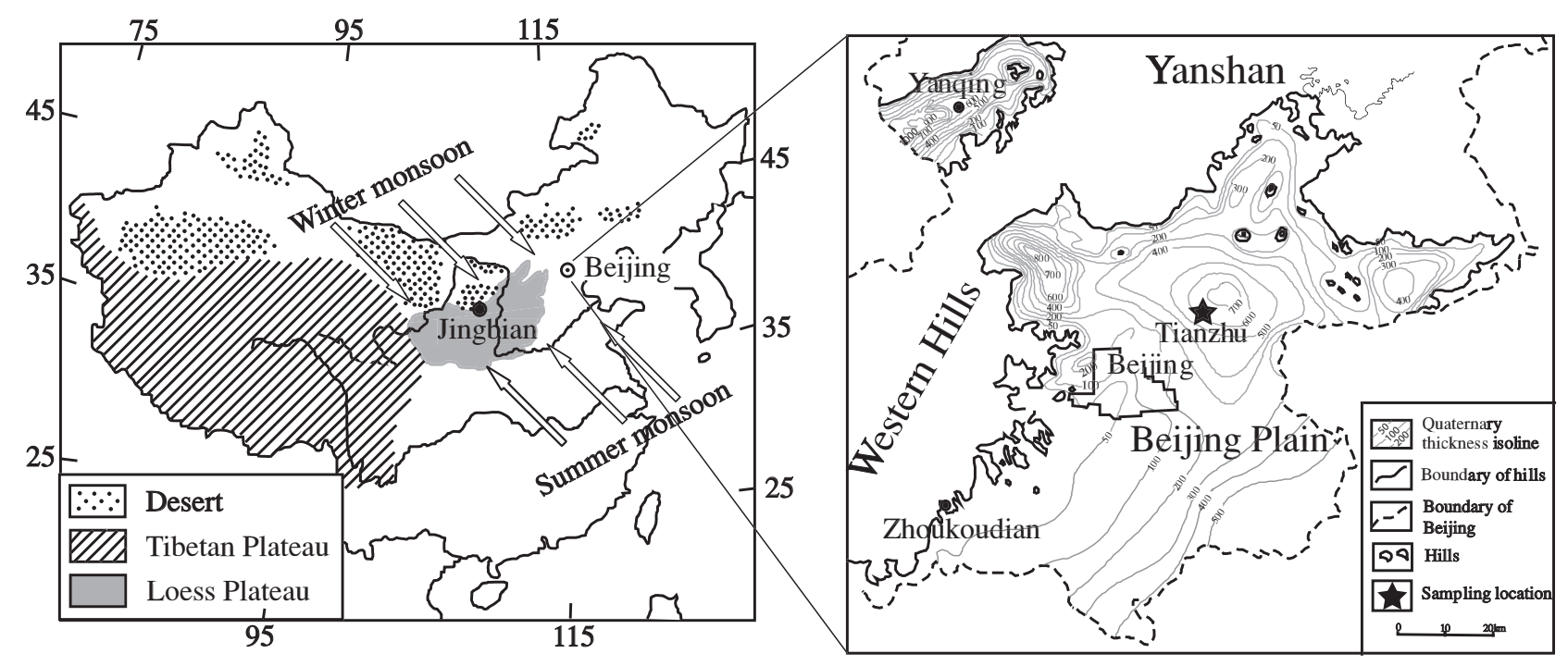

Fig. 1. The left map showing the Loess Plateau, Tibetan Plateau, deserts in North China, and location of the Jingbian section mentioned in the discussions (modified from Guo et al., 2002). The arrows show the directions of the summer and winter monsoons. The right figure showing the thickness of the Quaternary isoline in the Beijing Plain (modified from Li, 1994). The sampling locality of Tianzhu is marked in a black pentagon. The Yanshan and Western Hills are the main mountains. Other sites referred to in the text: Yanqing and Zhoukoudian.

pansion of arid regions during the Quaternary. Moreover, the Beijing Plain is regarded as a typical alluvial plain in a subsiding setting (Beijing Geology and Mineral Bureau, 1991; Li, 1994). Therefore, the Pleistocene fluvial deposits of the Beijing Plain are potentially valuable materials for a paleoclimate study. In the study reported here, a long sequence of 186.3-m-thick Pleistocene fluvial deposits at Tianzhu in the Beijing Plain is used to study the magnetic property over the last $800 \mathrm{ka}$.

In recent decades, magnetic susceptibility has been widely applied in studies of loess/paleosoil sequence, lacustrine and marine sections as a good proxy of climate change (Heller and Liu, 1984, 1986; Kukla et al., 1988; Dekkers, 1997; Evans et al., 1997; Fang et al., 1999; Brachfeld and Banerjee, 2000; Brachfeld et al., 2002; Boës et al., 2005; Garcin et al., 2006). However, the links between susceptibility and climate variations can be complex and casespecific. In the Chinese Loess Plateau, magnetic susceptibility is lower in the loess and higher in the paleosoil, which correlates to the glacial and interglacial periods, respectively (Heller and Liu, 1984, 1986; Hovan et al., 1989; Bloemendal et al., 1995; Heslop et al., 2000). In comparison, the loess in Alaska shows high susceptibility values, and the paleosol from Lubin in Poland shows low values. In these two latter cases, the magnetic susceptibility of the former resulted from the relatively strong wind transporting coarse grain-size magnetite during the glacial period (Begét et al., 1990), while that of the latter is inferred to correlate with the cool-wet periglacial climate when magnetic particles would have been destroyed through the gleying and eluviation (Heller and Evans, 1995).

The correlation between magnetic susceptibility of fluvial deposition and climate change is more complex. A study from the Lower Mississippi Valley sediments (Autin and Evans, 2001) shows that magnetic susceptibility has characteristic patterns associated with lithofacies variations. Nádor et al. (2003) argue that the systematic variations in magnetic susceptibility of the Pleistocene fluvial sequences in the Pannoman Basin, Hungary, correlated to the oxygen isotope variations of the ODP 677 site, suggesting that magnetic susceptibility may mainly correlate to climate as well as to pollen and gastropod data.

In study reported here, we analyzed the variations in magnetic susceptibility of the fluvial sequences and then discuss its correlation with climate changes. An extra pollen study was carried out for paleoclimatic indication. Based on the rock magnetism, sedimentary facies, and pollen data, we then reconstructed the climate change in the Beijing Plain over the last $800 \mathrm{ka}$.

\section{Regional Geology}

Beijing Plain lies in the northwest of the Great North China Plain, with Yanshan Mountain to the north and the Western Hills to the west (Fig. 1). The relative elevation or drop reaches $2295 \mathrm{~m}$. The main rivers of the area are the Yongding, Chaobai, Wenyu, Ju, and Juma, all of which are orientated approximately north-south, draining the northwest mountain zone and transporting sediments to the Beijing Plain to the southeast. At the present time, the average temperature in the Beijing Plain is $11.8^{\circ} \mathrm{C}$, and the average annual precipitation is about $650 \mathrm{~mm}$, with most of the precipitation falling in the summer. Due to the influence of the summer and winter monsoonal systems, there are strong seasonal variations in both temperature and precipitation in the Beijing Plain.

The tectonic basement of the Beijing area was established by the Yanshan orogeny during the Middle Jurassic to the Upper Cretaceous (Li, 1994; Chen et al., 2002), while the present physiognomy was shaped during the Cenozoic Himalayan tectonic movement (Chen et al., 2002). The northwest mountain zone and Beijing Plain started forming in the Neogene (Beijing Geology and Mineral Bureau, 1991). In the Quaternary, the northwest mountain zone was continuously uplifted, to an average capacity of ap- 
proximately $450 \mathrm{~m}$; this was accompanied by intense erosion and denudation (Beijing Geology and Mineral Bureau, 1991; Chen et al., 2002). At the same time, the southeast Beijing Plain was characterized by ongoing subsidence in the great range and was filled by quasi-continuous fluvial sequences (Li, 1994; Shan et al., 1994). These fluvial sequences consist predominantly of clay, silt, and sand supplied by rivers coming from the Yanshan Mountain and Western Hills (Beijing Geology and Mineral Bureau, 1991; Li, 1994; Chen et al., 2002).

In 2002, a borehole was drilled to a depth of $742 \mathrm{~m}$ at Tianzhu, facing the Wenyu River to the west, $30 \mathrm{~km}$ northeast of Beijing center (Fig. 1). The chosen area is one of the largest uninterrupted subsiding areas in the Beijing Plain and was filled by a 500- to 600-m-thick fluvial sequence in the Quaternary.

\section{Methods}

Samples of the top 186.3-m-thick sequence of the Tianzhu borehole were obtained at intervals of $20 \mathrm{~cm}$ and placed in $8-\mathrm{cm}^{3}$ cylindrical plastic boxes. A total of 891 samples were collected for rock magnetism analyses in the Key Laboratory of Paleomagnetism of the Institute of Geomechanics, Chinese Academy of Geological Sciences and also in the Paleomagnetic Laboratory of Nanjing University. Low-field magnetic susceptibility $(k)$ was measured using a Bartington MS2 kappameter, and the natural remanent magnetization (NRM) was measured using a 2G-755R cryogenic magnetometer. Isothermal remanent magnetization (IRM) was imparted with a pulse magnetizer at a forward field of $2.4 \mathrm{~T}$ (SIRM) and a backward field of 300 mT (IRM-300) and measured with a DSM-2 digital spinner magnetometer. The $S$-ratio and hard isothermal remanent magnetization (HIRM) were respectively calculated as:

$$
\begin{aligned}
S_{-300} & =\text { IRM }_{-300} / \mathrm{SIRM} \\
\mathrm{HIRM} & =\left(\mathrm{SIRM}_{-} \mathrm{IRM}_{-300}\right) / 2 .
\end{aligned}
$$

NRM, SIRM, IRM-300, and $k$ measurements were carried out on all samples. Additional measurements on pilot samples included the acquisition of IRM in a stepwise increasing forward field up to $2.4 \mathrm{~T}$ (IRM acquisition curve) and in a subsequent reverse field (backfield curve). A composite of IRMs were imparted along three orthogonal axes of a sample with strong $(2.4 \mathrm{~T})$, moderate $(0.4 \mathrm{~T})$, and weak $(0.12 \mathrm{~T})$ magnetic fields, respectively (Lowrie, 1990). The composite IRMs were then thermally demagnetized to obtain the unblocking temperature spectrums using an ASCTD48 thermal demagnetizer with an internal residual field lower than $10 \mathrm{nT}$. Thermomagnetic curves $(k-T)$ were measured in air up to $700^{\circ} \mathrm{C}$ using a CS-3 heating unit that was attached to a KLY-3S kappabridge.

In addition to the rock magnetism measurements, 20 samples were chosen for pollen analysis by the Northeast Institute of Geography and Agroecology, Chinese Academy of Sciences. Prior to the chemical procedure, one tablet of staghorn spores (about 6000 spores per tablet) was added to each sample for the calculation of the pollen concentration. Approximately $50 \mathrm{~g}$ per sample were crushed and then consecutively treated with $\mathrm{HCl}, \mathrm{KOH}, \mathrm{HCl}, \mathrm{HF}$, and $\mathrm{HCl}$. Following the chemical treatment, the pollen was collected by flotation with a mixture of $\mathrm{Zn}, \mathrm{HI}$, and $\mathrm{KI}$ and then placed on slides. The prepared slides were identified under a Leitz light microscope, usually at $40 \times$ magnification. The pollen sum of 17 samples was based on 300 grains, that of two samples was based on 400 grains, and that of one sample was based on 100 grains.

\section{Dating and Sedimentary Facies}

The Tianzhu borehole has previously been subjected to a detailed magnetostratigraphic study (Jia et al., 2004). Figure 2 shows the Zijderveld diagrams of alternating demagnetization of representative samples from the Tianzhu borehole. The magnetostratigraphic results show that the Brunhes/Matuyama boundary is located on the core at a depth of $175 \mathrm{~m}$ (Fig. 3). The age of the 186.3-m-thick fluvial sequence is deduced to be approximately $800 \mathrm{ka}$. Two geomagnetic excursion events were recorded in the Brunhes normal chron.

Spectrum analysis of magnetic susceptibility values between $175.4 \mathrm{~m}$ and $73 \mathrm{~m}$ from the Tianzhu borehole reveals predominance depth cycles of 34.1, 17.1, 10.2, 6.4, 5.1, 4.1, and $3.53 \mathrm{~m}$ (Fig. 4). The spectrogram shows that for the last $10 \mathrm{Ma}$ the frequencies of theoretical values of orbital eccentricity are, in order of decreasing amplitude, $404 \mathrm{ka}, 95 \mathrm{ka}$, $124 \mathrm{ka}, 99 \mathrm{ka}$, and $131 \mathrm{ka}$ (Hinnov, 2004) (Table 1); the theoretical periods of obliquity and precession are $41 \mathrm{ka}$, $39.6 \mathrm{ka}, 53.6 \mathrm{ka}, 23.7 \mathrm{ka}, 22.4 \mathrm{ka}$, and $19.1 \mathrm{ka}$, respectively (Hinnov, 2004) (Table 1). A simple period proportion of three orbit parameters are close to 20: 5(6): $2: 1$. The proportion of the predominance depth cycles in our study is approximately 9.66: 4.84: 2.89: 1.81: 1.44: 1.16: 1 . Therefore, the main predominant spectrum of depth cycle $17.1 \mathrm{~m}$ should correspond to the $95 \mathrm{ka}$ or $99 \mathrm{ka}$ eccentricity periods. In our study, the $95 \mathrm{ka}$ eccentricity period with much higher amplitude was selected to calculate the accumulation rate $(\mathrm{AR})$ of $18 \mathrm{~cm} / \mathrm{ka}$ between $175.4 \mathrm{~m}$ and $73 \mathrm{~m}$. Using a $18 \mathrm{~cm} / \mathrm{ka}$ rate, the predominant depth cycles of magnetic susceptibility from the Tianzhu borehole were transformed to the following time scale values: $189.5 \mathrm{ka}, 95 \mathrm{ka}, 56.7 \mathrm{ka}$, $35.6 \mathrm{ka}, 28.3 \mathrm{ka}, 22.8 \mathrm{ka}$, and $19.6 \mathrm{ka}$ (Table 1). In addition to the selected prominent $95 \mathrm{ka}$ eccentricity periods, four other time values were regarded as being a good match for the obliquity and precession theoretical periods. The time values $56.7 \mathrm{ka}$ and $35.6 \mathrm{ka}$ could be an effect of obliquity variations, and the other two time values, $22.8 \mathrm{ka}$ and $19.6 \mathrm{ka}$, indicated the precession variations. Both the predominance depth cycles ratios and the absolute time values strongly support the interpretation that these are true Milankovitch cycles.

Therefore, based on the accumulation rate between $175.4 \mathrm{~m}$ and $73 \mathrm{~m}$ and the $\mathrm{B} / \mathrm{M}$ boundary at $175 \mathrm{~m}$ aged $780 \mathrm{ka}$, the second geomagnetic excursion event (79$77 \mathrm{~m}$ ) of Tianzhu borehole can be reliably dated at 247$236 \mathrm{ka}$, which is likely correlated to Pringle Falls (215$205 \mathrm{ka}$ ) or Calabrian Ridge 0 (265-255 ka) (Langereis et al., 1997). The correlation between magnetic susceptibility of the Tianzhu borehole and the $\delta^{18} \mathrm{O}$ of the ODP 677 site (referred to in Section 5.2) indicates that the low magnetic susceptibility in the second geomagnetic excursion event should be correlated to the glacial stage. Because the 


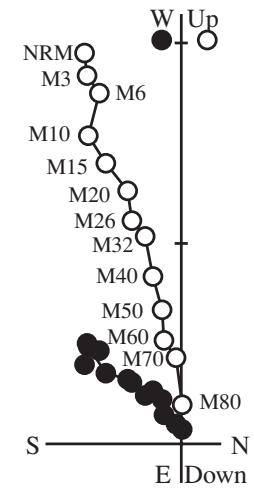

Z16: $21.99 m \quad$ Scale: $1 \mathrm{e}-2 \mathrm{~A} / \mathrm{m}$

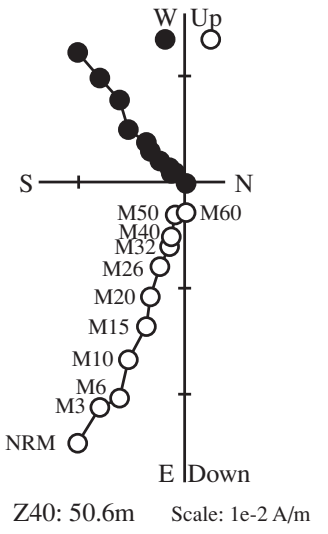

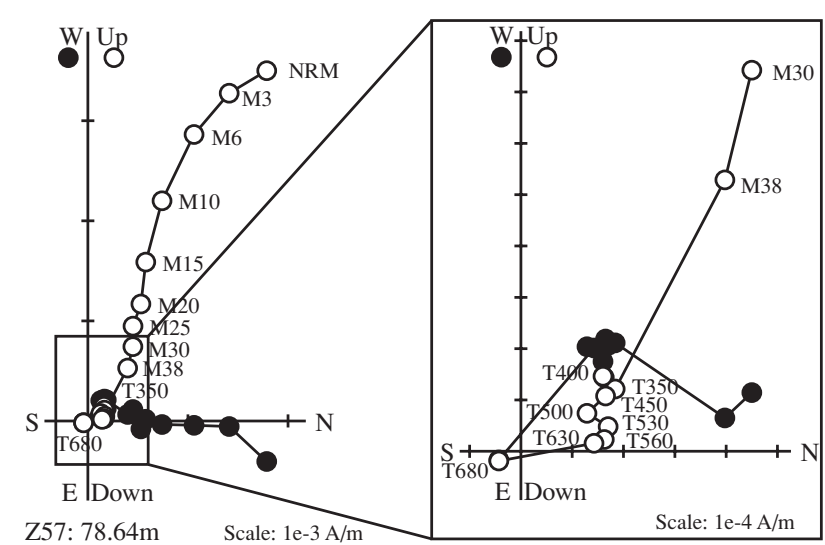

Z57: $78.64 \mathrm{~m}$

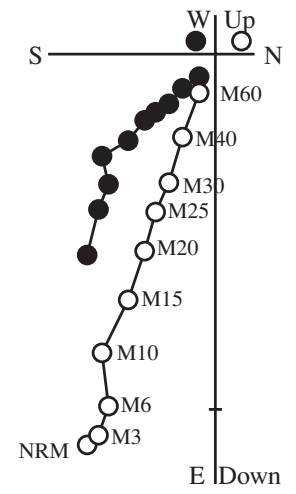

Z105: $162.2 \mathrm{~m} \quad$ Scale: $1 \mathrm{e}-2 \mathrm{~A} / \mathrm{m}$

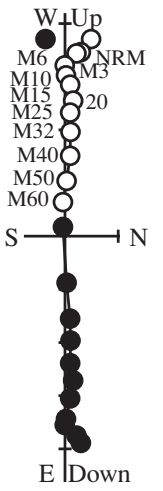

Z134: $193.5 \mathrm{~m}$

Scale: $1 \mathrm{e}-2 \mathrm{~A} / \mathrm{m}$

Fig. 2. Orthogonal projections of progressive alternative demagnetization data for the representative samples of the Tianzhu borehole. Solid (open) circles refer to the projection on the horizontal (vertical) plane. The depth of each sample is indicated. Demagnetized steps T350 and M38 refer to thermal demagnetization $\left({ }^{\circ} \mathrm{C}\right)$ and alternating demagnetization (milli-Tesla), respectively.

Table 1. Comparison of various values between astronomic theoretical periods and predominant cycles of magnetic susceptibility from Tianzhu borehole.

\begin{tabular}{ccc}
\hline Astronomic theoretical periods & \multicolumn{2}{c}{ Predominant cycles } \\
\cline { 2 - 3 }$(\mathrm{ka})$ & Depth $(\mathrm{m})$ & Time $(\mathrm{ka})$ \\
\hline $404($ Eccentricity 1) & 34.1 & 189.5 \\
131 (Eccentricity 5) & & \\
$124($ Eccentricity 3) & & \\
$99($ Eccentricity 4) & 17.1 & 95 \\
*95(Eccentricity 2) & 10.2 & 56.7 \\
$53.6($ Obliquity 3) & & \\
41.0 (Obliquity 1) & 6.4 & 35.6 \\
39.6 (Obliquity 2) & 5.1 & 28.3 \\
& & \\
23.7 (Precession 1) & 4.1 & 22.8 \\
22.4 (Precession 2) & 3.53 \\
19.1 (Precession 3) & Accumulation rate: $18 \mathrm{~cm} / \mathrm{ka}$ \\
\hline
\end{tabular}

*The main astronomic theoretical period identified from the predominant cycles of magnetic susceptibility from the Tianzhu borehole.

Pringle Falls and Calabrian Ridge 0 excursion events were referred to as Marine Isotope Stage (MIS) 7 and MIS 8, respectively, it is more reasonable to correlate the second geomagnetic excursion with Calabrian Ridge 0. The topmost parts of the sediments in the Beijing Plain have not been eroded, and their ages are assigned to the Holocene (Beijing Geology and Mineral Bureau, 1991; Li, 1994). Based on the average sedimentary rate in the Brunhes chron, the age of the first geomagnetic excursion event is approximately simultaneous with the Blake event (120-110 ka) (Langereis et al., 1997).

Macroscopic observation of the core shows that the whole sedimentary sequence is characterized by silty clay and silt or sand interbeds (Fig. 3). Sand is prevalent in the sequence except for the upper parts of the sections where layers of fine sand approximately 1-3 m thick are intercalated in the thick silt. Sand mainly occurs as two different types, with a form of fine- to coarse-grained, massive, or well-sorted, as trough cross-stratified, ripple-laminated sand layers varying in thickness from approximately 5 to $15 \mathrm{~m}$ (e.g. 133-118 m) and enclosed by the clay or silt with lenticular structure (e.g., 72-63 m). Rare horizontal stratifications of silty clay can be found between the thick layers of sands, characterized by being thick in the middle of the sequence $(>5 \mathrm{~m})$ and thin in the crest and bottom $(1-3 \mathrm{~m})$. Pure clay occurs rarely. Some thin black organic-rich clay layers are mostly related to lacustrine deposits.

The sedimentary facies associations described above are considered to have formed in the alluvial plain of a braided river system, where predominantly sands enclose finegrained deposits. The thick layers of sand are interpreted 


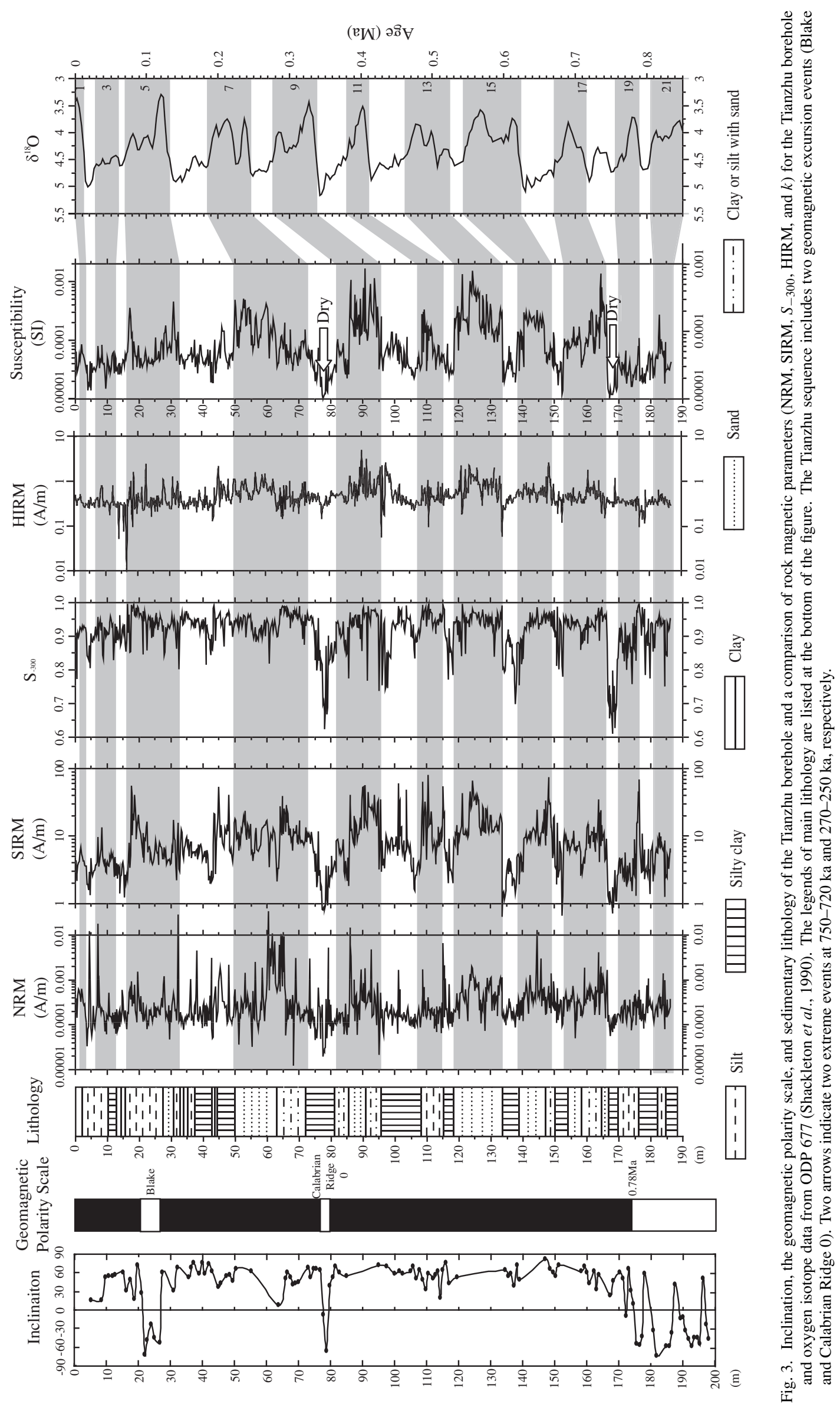




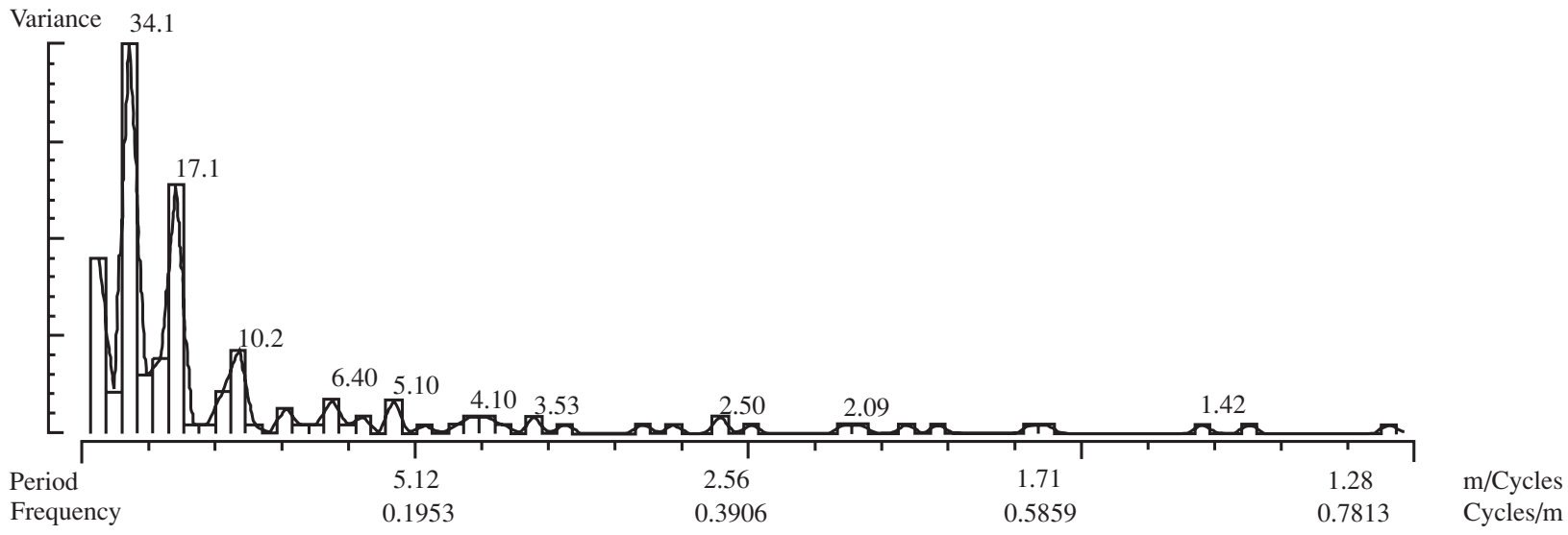

Fig. 4. Spectrum analysis of magnetic susceptibility curve between 175.4 and $73 \mathrm{~m}$ from the Tianzhu borehole.

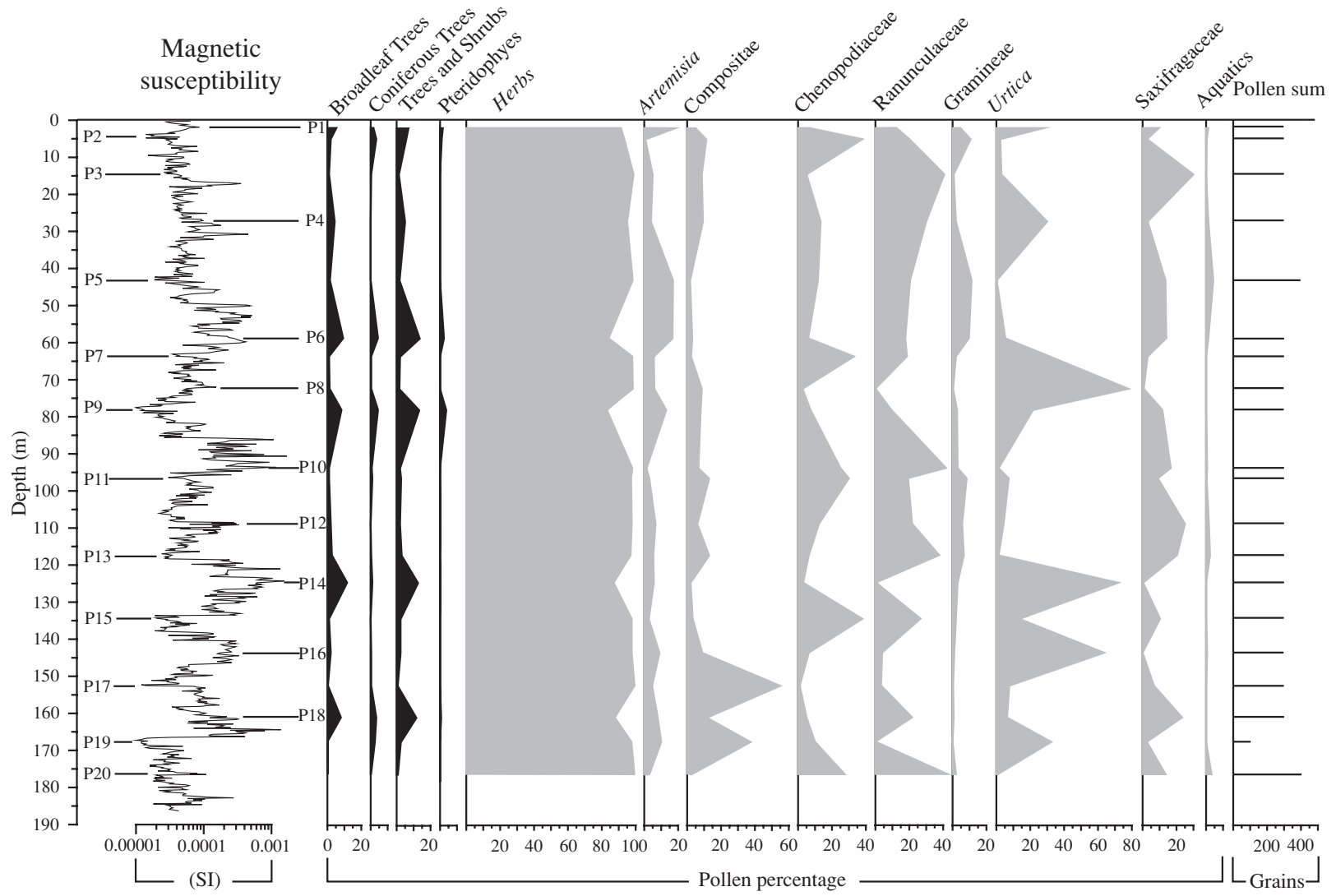

Fig. 5. Pollen percentage diagram of 20 samples from the Tianzhu borehole. The pollen data were plotted against the magnetic susceptibility proxy.

to be channel bars or channels, and the silt, clay silt, and silty clay are interpreted as overbank fines. The clay or silt enclosing the sand is regarded as stagnant depositions under relatively strong drainage. The stagnant layers always overlie the erosional bases and are located at the bottom of fluvial sedimentary cycle.

\section{Results}

\subsection{Pollen results}

Because the link between susceptibility variations and climate could be case-specific, a reliable climate indicator is needed for comparison with magnetic susceptibility, with the aim of validating whether magnetic susceptibility values reflect a cold or warm climate in the case of the Tianzhu fluvial sequence. Twenty samples with relatively high or low values in magnetic susceptibility, respectively, were selected for pollen analysis (Fig. 5).

The pollen analysis results of 20 samples are characterized by the dominance of pollen from herbs and low percentages of pollen from trees and shrubs. Fern spores occur occasionally and only account for approximately 0 to $3.67 \%$ of all pollen. Pollen from herbs are primarily of mesophyte and xerophile origin, such as Urtica, Compositae, Ranunculaceae, Chenopodiaceae, Saxifragaceae, Artemisia, and 


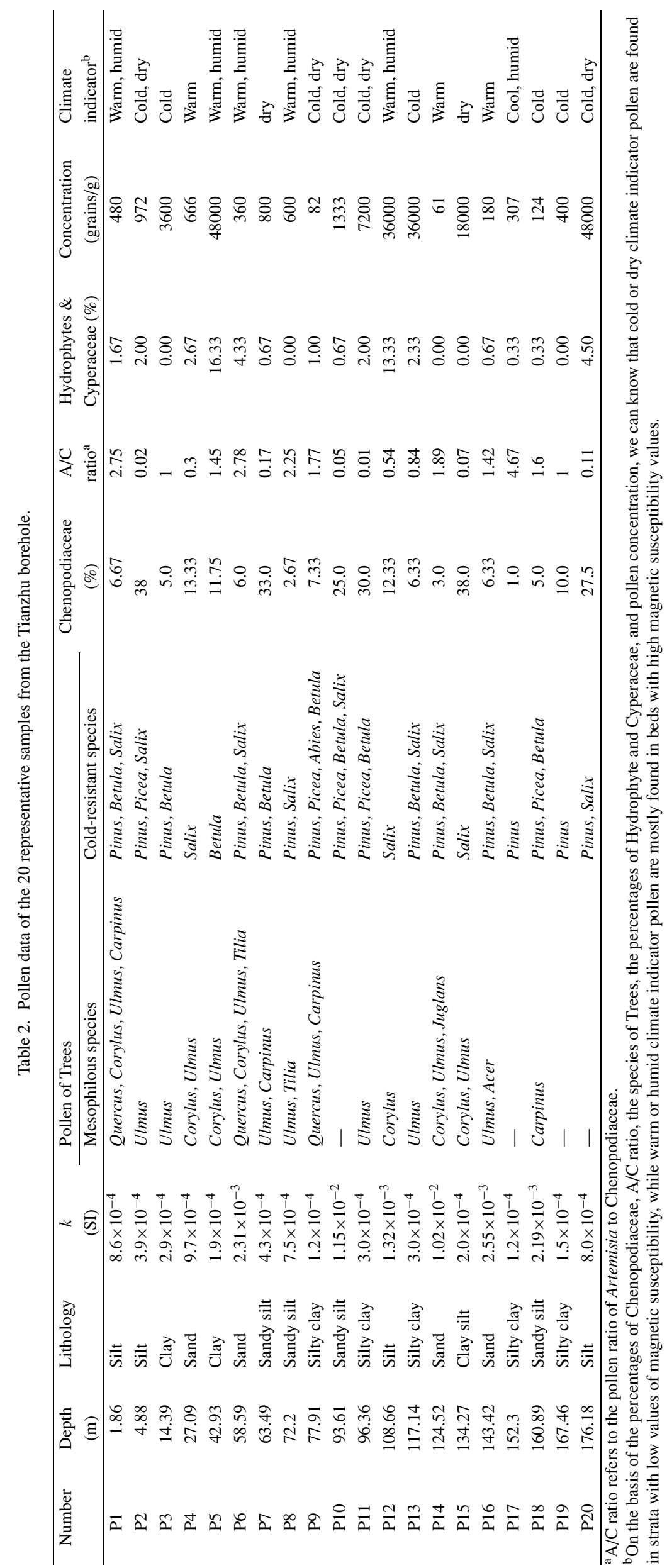


Gramineae (Fig. 5). Pollen from hydrophytes is scarce, with most from Typha and Myriophyllum. The pollen assemblage suggests a relatively semi-dry or dry climate in the mass, indicating that the Beijing area has been characterized by grassland cover and a low percentages of trees since the middle Pleistocene.

The combination of tree pollen species, the percentages of Chenopodiaceae pollen, the A/C ratio (ratio of Artemisia to Chenopodiaceae), the percentages of Cyperaceae and hydrophyte pollen, and total pollen concentration were used to develop the climate indicator (Table 2). The presence of tree pollen, characterized by high percentages of Quercus, Corylus, Ulmus, Carpinus, Tilia, and Juglans, can be considered to indicate a warm climate, while the samples dominated by pollen of Pinus, Betula, Picea, and Abies are interpreted as deposits in a glacial period. Samples P2, P7, P10, P11, P15, and P20, with higher percentages of Chenopodiaceae and little hydrophyte pollen, imply a dry paleoclimate condition (Table 2). As the main representative of the components of the pollen assemblage, the $\mathrm{A} / \mathrm{C}$ ratio can be regarded as a humidity proxy in arid and semi-arid areas (e.g. El-Moslinmany, 1990; Gasse et al., 1991; Van Campo and Gasse, 1993; Li et al., 2005). The higher A/C ratio means a larger steppe component in regional vegetation and higher humidity (Huang et al., 2007). Therefore, the relatively higher $\mathrm{A} / \mathrm{C}$ ratio of samples $\mathrm{P} 1, \mathrm{P} 6, \mathrm{P} 8$, and $\mathrm{P} 17$ represents a relatively humid climate. On the contrary, the lower $\mathrm{A} / \mathrm{C}$ ratio of samples $\mathrm{P} 2, \mathrm{P} 7, \mathrm{P} 10, \mathrm{P} 11, \mathrm{P} 15$, and $\mathrm{P} 20$ indicates an arid climate (Table 2). A large amount of organic matter was observed in the P5 and P12 samples when examined microscopically. Both of these samples have the highest percentage of hydrophyte and Cyperaceae pollen, which grow under wet conditions, such as a marsh (Table 2). The greater pollen concentration in P5 may imply that moderate climate conditions at that time supported a rich plant assemblage. The lower pollen concentration and lack of Cyperaceae and hydrophyte pollen in sample P9 may indicate an arid and barren environment. However, the lower pollen concentration of P14 was difficult to interpret because of its coarse lithology, which did not facilitate the preservation of a mass of pollen. In conclusion, we suggest that samples P1, P4, P5, P6, P8, P12, P14, and P16 were formed during a period of warm or humid climate and that the others may have persisted during the cold or dry climate (Table 2).

The pollen data were plotted against the magnetic susceptibility proxy (Fig. 5). Samples P1, P4, P6, P8, P12, $\mathrm{P} 14$, and P16, in which the pollen results indicated a warm or humid climate, coincided with relatively high values of $k$, while samples $\mathrm{P} 2, \mathrm{P} 3, \mathrm{P} 7, \mathrm{P} 9, \mathrm{P} 11, \mathrm{P} 13, \mathrm{P} 15, \mathrm{P} 17, \mathrm{P} 19$, and $\mathrm{P} 20$, which had the relatively low $k$ values, correlated with pollen yielded under a cold or dry climate. However, three samples did not fit the correlation between magnetic susceptibility and pollen results. The reason for this lack of correlation for samples P10 and P18 is unclear, but it may be related to the incompact and coarse sediments of these samples not being suitable for the pollen preservation. With respect to sample $\mathrm{P} 5$, the magnetic minerals were diluted by masses of organic matter, which reduced the magnetic susceptibility. Sample P5 can be considered to be formed in the lake sedimentary facies, which is different from fluvial sediments in terms of the mechanism of magnetic enrichment. When these last three samples were removed from the analysis, the pollen results of the remaining 17 samples fit well with magnetic susceptibility, suggesting that magnetic susceptibility records can reflect climate changes in the Tianzhu fluvial sequence, with high $k$ values indicating a warm or humid climate condition and low $k$ values correlating with a cold or dry climate condition.

\subsection{Comparison of magnetic susceptibility with the $\delta^{18} \mathrm{O}$ of the ODP 677 site}

The pollen results suggest that magnetic susceptibility is a valuable paleoclimate proxy of the Tianzhu fluvial sequence. The magnetic susceptibility curve shows a cyclic pattern, indicating a warm-cold climate circulation since the Middle Pleistocene. Based on an age assignment of the topmost parts of Tianzhu borehole dated as the Holocene, the B/M boundary, and two excursion events of Blake and Calabrian Ridge 0, the magnetic susceptibility curve is correlated with the oxygen isotope record of the ODP 677 site since $800 \mathrm{ka}$, with high/low $k$ values corresponding to the oxygen isotope interglacial/glacial stages (Shackleton et al., 1990) (Fig. 3). The oxygen isotope record of the ODP 677 site is regarded as the best global climate proxy for the entire Pleistocene, which is tuned to an orbitally based ice volume model for the Earth (Shackleton et al., 1990). In our study, the magnetic susceptibility curve fit well with the oxygen isotope record of the ODP 677 site, suggesting that magnetic susceptibility indeed plays a major role as a climate indicator of the fluvial sediments. Thus, it can be considered that the Tianzhu fluvial succession was primarily controlled by global climate change.

\subsection{Rock magnetic results}

In order to identify the magnetic mineralogy, we performed IRM acquisition studies, thermal demagnetization studies of composite IRMs, and $k$ - $T$ thermomagnetic analyses. The acquisition of IRM was assayed in 48 samples, and the representative results of 14 samples are plotted in Fig. 4. The IRM acquisition curves can be grouped into two types. Samples from the interglacial intervals are nearly saturated at $300 \mathrm{mT}$, indicating a predominance of low-coercivity magnetite/maghemite (Fig. 6). On the other hand, samples from the glacial periods show quasi-saturation around $300 \mathrm{mT}$, and magnetization increases gradually up to approximately $2 \mathrm{~T}$, suggesting a composite of low and highcoercivity minerals. The backfield curves show that the interglacial samples generally have a lower coercivity of remanence $\left(B_{\mathrm{cr}}\right)$, approximately between 69 and $40 \mathrm{mT}$. However, the glacial samples display an overlap of high coercivity $>100 \mathrm{mT}$ and $<60 \mathrm{mT}$. In addition, the coarser samples usually have a lower $B_{\mathrm{cr}}$ for both interglacial and glacial samples, implying the presence of multi-domain grain-size magnetite.

Thermal demagnetization of composite IRMs was performed on 15 samples. Four typical measurement results are shown in Fig. 7. These results indicate that a low coercivity component was unblocked at about $580^{\circ} \mathrm{C}$, reflecting the predominance of magnetite. The pronounced change in magnetization in the lower field component curves between $300^{\circ} \mathrm{C}$ and $350^{\circ} \mathrm{C}$ may imply the breakdown of maghemite. Both high and medium field components are relatively 

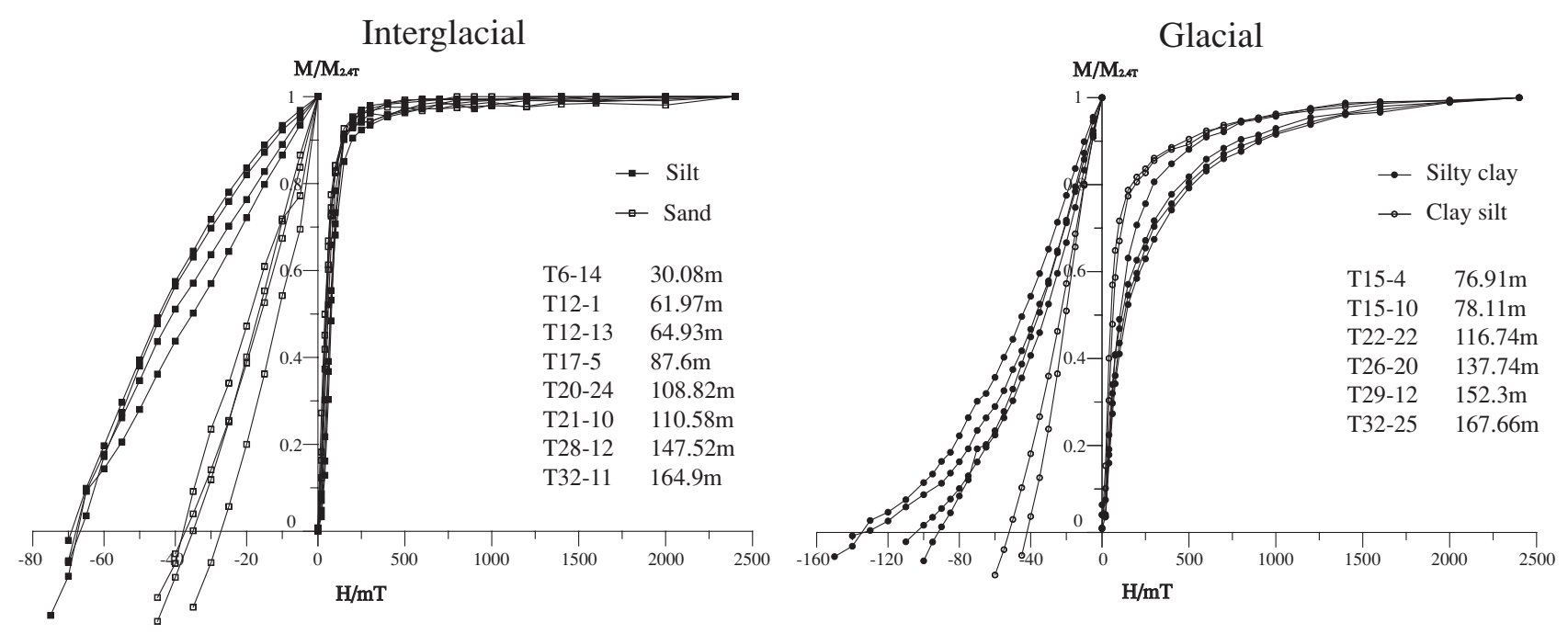

Fig. 6. IRM acquisition and backfield curves of selected samples from the Tianzhu borehole. The saturation field attains $2.4 \mathrm{~T}$ for the IRM acquisition.
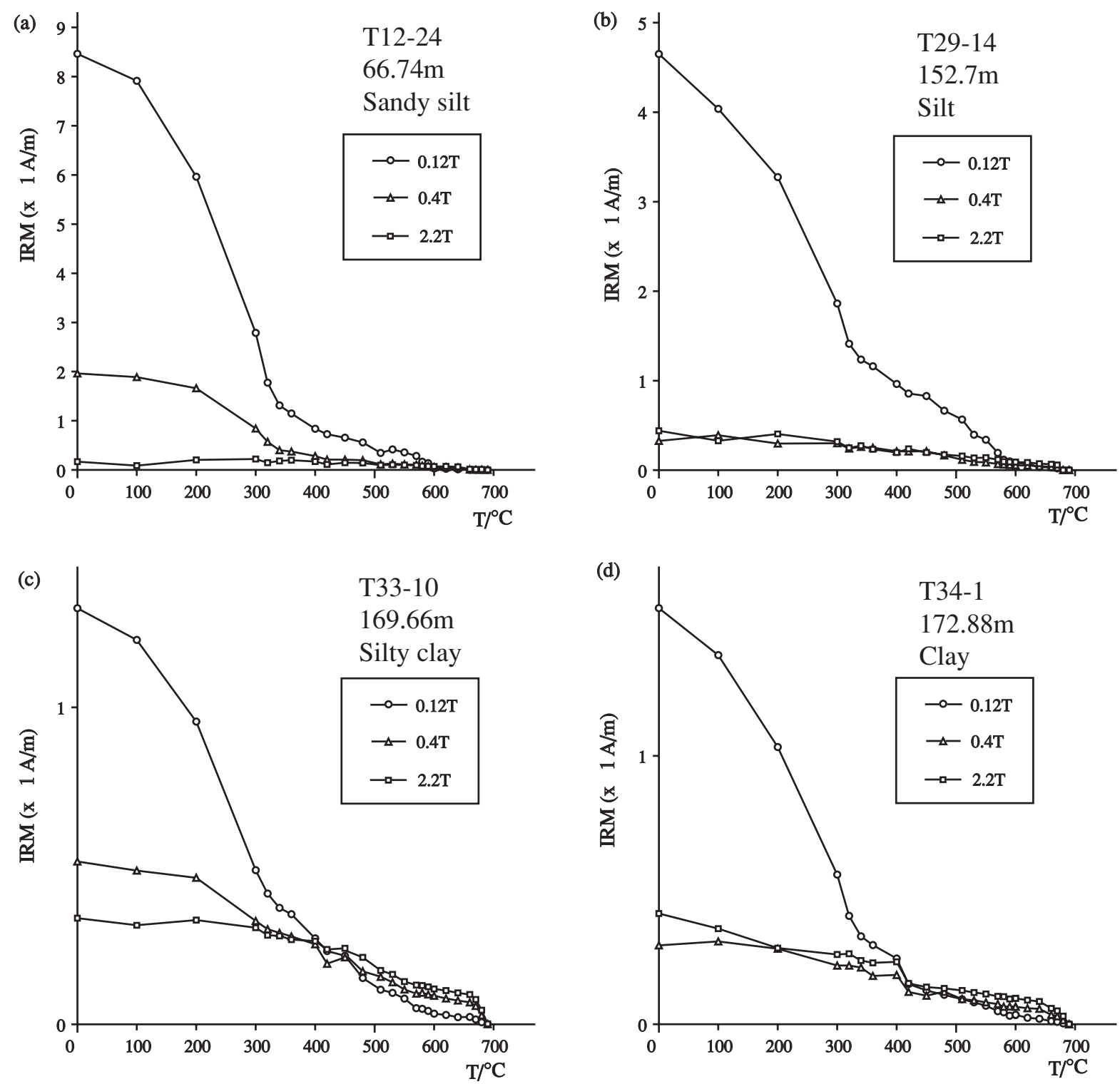

Fig. 7. Thermal demagnetization behavior of composite IRMs imparted along three orthogonal directions. a, b refer to interglacial samples, $c, d$ refer to glacial samples. 

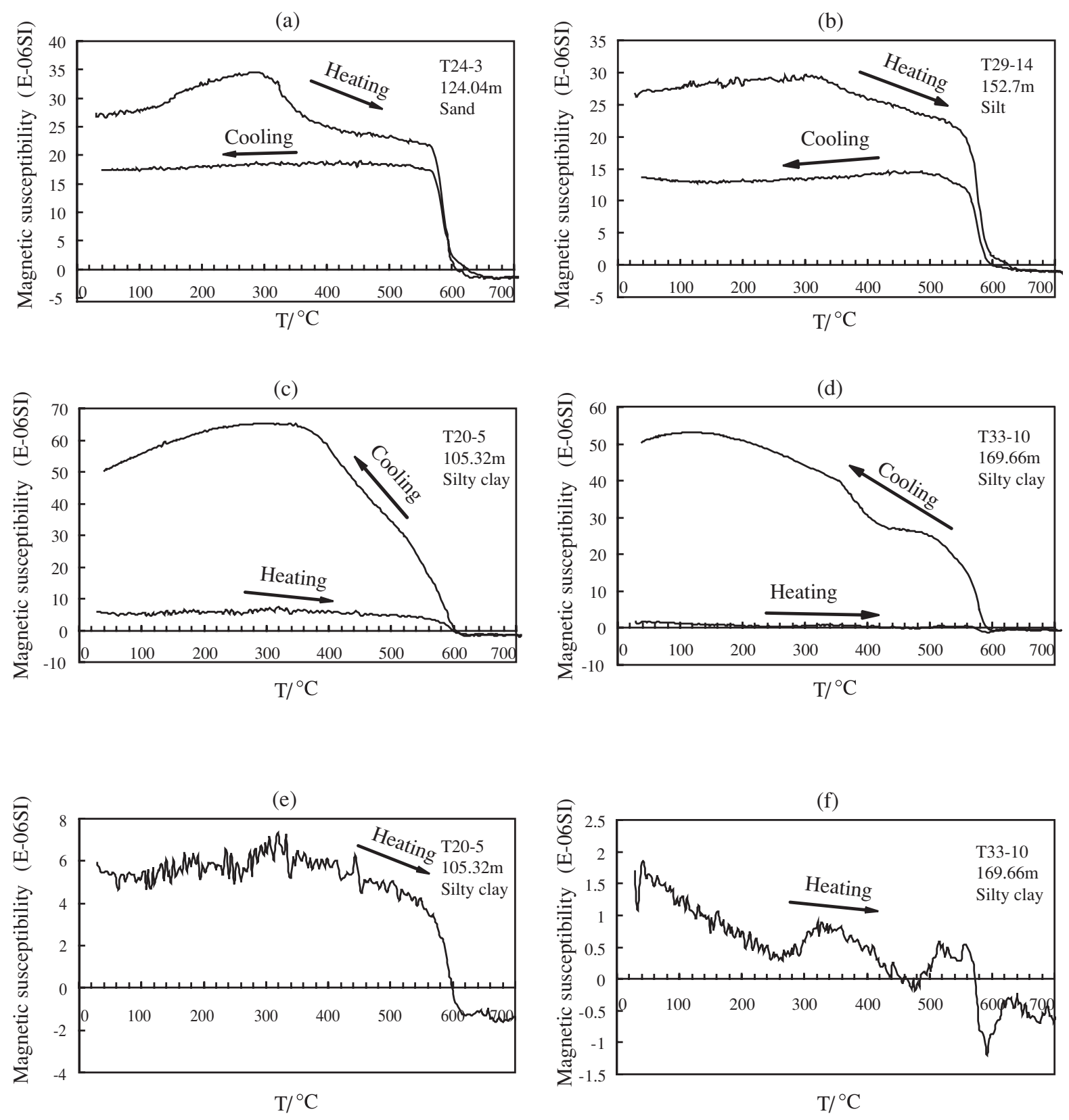

Fig. 8. Temperature dependence of magnetic susceptibility of representative samples. Thermomagnetic curves were measured in an atmospheric environment. Heating and cooling processes are shown by arrows. a, b refer to interglacial samples, c, d refer to glacial samples. e, f are the enlarged heating curve of $\mathrm{c}, \mathrm{d}$, respectively.

weak, indicating the presence of hematite, which has an unblocking temperature of $680^{\circ} \mathrm{C}$. The results also show a relatively higher proportion of hematite in glacial samples (Fig. 7(c) and (d)) than in interglacial samples (Fig. 7(a) and (b)).

Figure 8 shows the $k-T$ thermomagnetic curves of the interglacial samples (Fig. 8(a) and (b)). These curves show a distinctive Curie-point of magnetite at $580^{\circ} \mathrm{C}$, which is in accordance with the results of the thermal demagnetization of orthogonal IRMs. A pronounced declining behavior between $300^{\circ} \mathrm{C}$ and $400^{\circ} \mathrm{C}$ may reflect either the Curie-point of some magnetic minerals or the breakdown of thermally unstable minerals, such as the conversion of maghemite to hematite. The cooling curve shows that magnetite is the final product during the heating process, and the susceptibility is lower than the heating curve. These results suggest that the magnetic mineral with the unblocking temperature around $350^{\circ} \mathrm{C}$ is probably maghemite, which has also been demonstrated by thermal demagnetization of composite IRMs. The susceptibility of the heating curves of the glacial samples (Fig. 8(c) and (d)) is too low to estimate magnetic minerals. We can only estimate the presence of magnetite from the enlarged heating curve of Fig. 6(c) (Fig. 8(e)). The enlarged heating curve in Fig. 8(d) shows no characteristics (Fig. 8(f)). Transformation of clay minerals to silicates during the high temperature heating process may be the cause of this large change in susceptibility between the heating and cooling processes, in which some irons were detached and formed new magnetic minerals.

Therefore, the rock magnetic results suggest the presence 

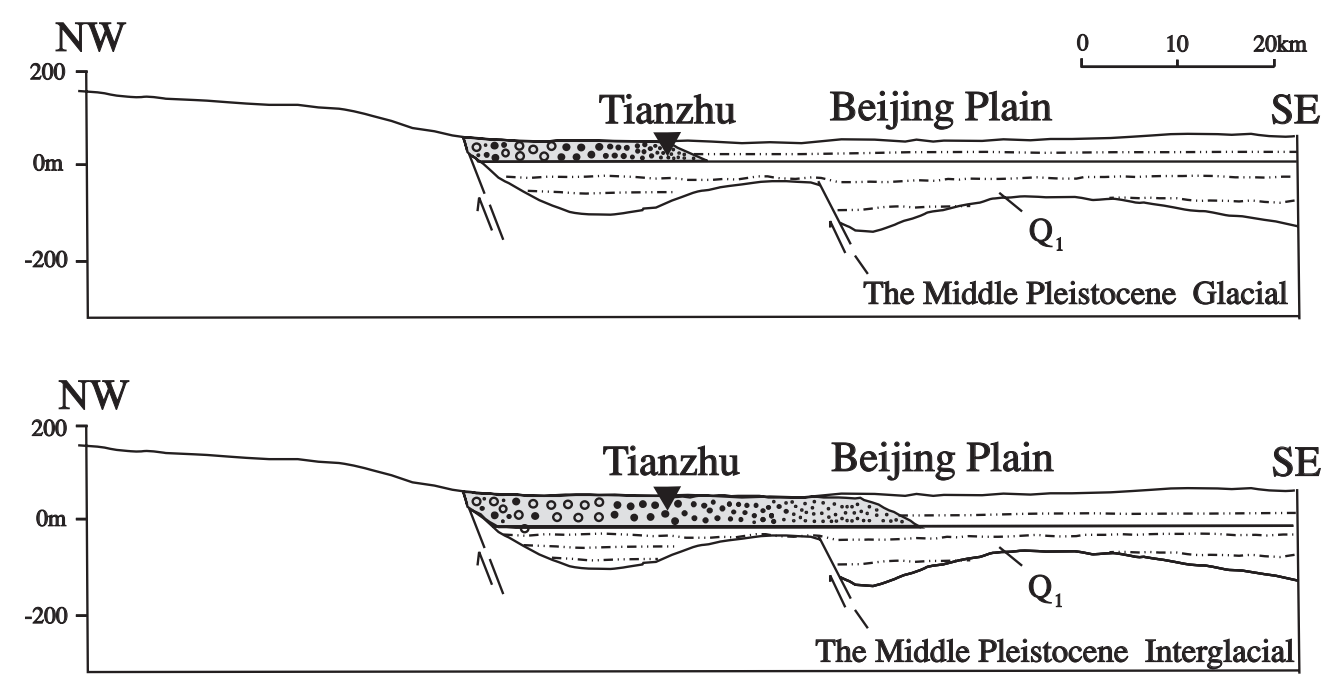

\begin{tabular}{|c|c|c|c|c|c|}
\hline 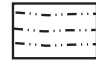 & Fluvial sediments & & $\begin{array}{l}\text { Once fluvial } \\
\text { sedimentary cycle }\end{array}$ & $\begin{array}{ll}0 & 0 \\
0 & 0\end{array}$ & Conglomerate \\
\hline$\because \because \because$ & Sand & 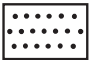 & Silt & :-1.:- & Clay \\
\hline
\end{tabular}

Fig. 9. Sedimentation models in the Beijing plain since the Middle Pleistocene. $\mathrm{Q}_{1}$ indicates the sediments in the Lower Pleistocene. The triangle marks the location of Tianzhu borehole.

of magnetite, hematite, and maghemite in the fluvial sediments. Magnetite is the main magnetic carrier in the interglacial stages, and glacial stages are characterized by the dominance of hematite.

\section{Discussion}

\subsection{Climate change and fluvial cycles}

Fluvial cycles may take the form of autocycles, caused by floods and avulsion, and allocycles, representing external forces, such as climate, tectonics, and base-level changes (Xu et al., 1996a, b; Nádor et al., 2003). In fact, fluvial sedimentation displays the results of both autocycle and allocycle phenomena, which cannot be clearly distinguished in each case (Einsele et al., 1991). The observed sedimentary facies associations in the Tianzhu borehole, such as channel bars, channels, and overbank fines, are considered to be products mainly of autocycle processes. Nevertheless, the main fluvial sedimentary cycle in the Tianzhu borehole represented by alternations between sand/silt and silty clay was mostly controlled by allocycle processes. Studies of paleochannels in the North China Plain have shown that the mountain uplift, subsidence of the plain, and tectonic movement of the basement since the Cenozoic interacted with the flashy fluvial regime involving high sediment loads and frequent channel changes (Xu et al., 1996a). However, variations in the fluvial sequences due to tectonic changes do not show any cyclic pattern in the Tianzhu borehole. The borehole under study was located at the front edge of the piedmont plain zone, which was less influenced by baselevel changes associated with sea-level fluctuations during the Pleistocene (Li, 1994; Wu et al., 1996a, b). Therefore, the cyclicity observed in the successions was most likely climate-controlled.

The pollen results and comparison of magnetic susceptibility with the $\delta^{18} \mathrm{O}$ of the ODP 677 site demonstrate that magnetic susceptibility is a reliable climate proxy. Our comparison of magnetic susceptibility with the lithology reveals that the high values of magnetic susceptibility are in the strata of sand and silt in the interglacial periods, whereas they are low in the strata of silty clay in the glacial periods. The correlation between magnetic susceptibility and lithology seems to confirm the view that climate change was the main factor controlling the fluvial sedimentary cycles in the studied area.

The model propounded by Nádor et al. (2003) in a similar fluvial sedimentary environment was used to illustrate the relation between the climate changes and variations in lithology and magnetic susceptibility. In their model, climate controls lithology and magnetic susceptibility principally through changing the fluvial discharge and transport capacity (Nádor et al., 2003).

Based on their model, we propose that although strong weather processes and limited vegetation increased sediment supply to the rivers during the dry and cold glacial periods, the average discharge and transport capacity of the rivers were low due to low precipitation. Consequently, the rivers were unable to carry coarse-grained sand or silt over a long distance. This low discharge and transport capacity led to a low detrital magnetic mineral input. On the other hand, although the extended vegetation resulted in a limited supply of sediments during the humid and warm interglacial periods, the higher discharge and higher transport capacity of the rivers could enable them to carry richer and coarser grain-size sediments to further distances than during glacial periods due to abundance of precipitation. The large amount of input sediments accompanied with rich detrital magnetic minerals yielded high magnetic concentration that resulted in the high magnetic susceptibility values (Fig. 9). 


\subsection{Climate change, rock magnetic records, and ex-} treme events

The rock magnetic results and pollen analyses of the Tianzhu borehole revealed the palaeoclimate changes in the Beijing Plain since $800 \mathrm{ka}$, which correlate well with the ODP 677 oxygen isotope proxy. According to this correlation, we argue that the sediments were subjected to frequent warm-cold fluctuations during the last $800 \mathrm{ka}$. The glacialinterglacial cycles are the most important climate changes in Beijing area since the middle Pleistocene. The pollen and micropaleontology recorded in the Yanqing Basin, located in the northwest part of the Beijing Plain, show that the climate has changed from a warm and humid condition to a cold and dry or semi-dry one since the Middle Pleistocene (Fig. 10). The sediments at Zhoukoudian cave located $50 \mathrm{~km}$ southwest of Beijing city also record these cold and warm alternation climate changes (Zhou et al., 2000). Based on cluster and factor analyses of mammal fossils and spore/pollen in the cave sediments, the weathering index, and trace element content, Zhou et al. (2000) proposed a synthetic vicarious climatic index that indicates that the cave sediments with a thickness of $40 \mathrm{~m}$ may be correlated with stages $11-19$ of $\delta^{18} \mathrm{O}$ curve of the deep sea. However, compared with the results presented in the Yanqing Basin, and the Zhoukoudian cave listed in Fig. 10, our results show a continuous high resolution of climatic changes with more accurate time constraints.

Five magnetic parameters (NRM, SIRM, $S_{-300}$, HIRM, and $k$ ) that vary with depth are shown for comparison with the oxygen isotope variations of the ODP 677 site in Fig. 3. A close correlation of susceptibility with NRM, SIRM, $S_{-300}$, and HIRM shows that the five parameters have high values in the interglacial periods and low values in the glacial periods. SIRM and $k$ are relatively sensitive to variations in ferromagnetic mineral concentrations. The $S_{-300}$ ratios are $>0.9$ in the interglacial periods, which reflects the dominance of low-coercivity minerals, such as magnetite. The low $S_{-300}$ ratios $(<0.85)$ in the glacial periods are interpreted as the dominance of high-coercivity minerals, such as hematite. HIRM represents the amount of high coercivity minerals.

It is noted that the lowest values of $k, \mathrm{NRM}, \mathrm{SIRM}$, and $S_{-300}$ in the sediments are found in the intervals of 169-166 and 81-73 m, which correspond to MIS 18 (750-720 ka) and MIS8 (270-250 ka), respectively (Fig. 3). Based on the model of climate controlling fluvial cycles in the Beijing Plain, we suggest that the higher inputs of magnetic minerals, as a result of increasing precipitation, resulted in higher values of $k$ and SIRM in the interglacial periods and that decreasing precipitation in the glacial periods reduced the inputs of magnetic minerals, resulting in lower values of $k$ and SIRM. Therefore, the concentration parameters $k$ and SIRM can be considered to be reliable and direct proxies of precipitation in this study. HIRM shows the opposite variations with $S_{-300}$, implying that $S_{-300}$ is associated with variations in low-coercivity magnetic minerals in fluvial input. Therefore, $S_{-300}$ may also be considered to be a proxy of precipitation. The lowest values of $k$, SIRM, and $S_{-300}$ indicate the lowest precipitation occurred at 750-720 ka and 270-250 ka, which are regarded as two extreme events in the Tianzhu fluvial record. The lowest percentages of trees and shrubs pollen at approximately $750 \mathrm{ka}$ and the highest percentages of pollen of cold-resistant species at approximately $250 \mathrm{ka}$ suggest that both intervals are the driest and coldest periods on the Beijing Plain. The records for the Yanqing Basin and Zhoukoudian cave are also consistent with the dry-cold conditions during these two intervals (Fig. 10).

A continuous record of sand content in Jingbian which is situated at the north edge of the Loess Plateau, shows that sand grain sizes changed abruptly at approximately $700 \mathrm{ka}$ and $200 \mathrm{ka}$, indicating that the Mu-Us Desert gradually migrated southward (Ding et al., 2005). Analyses of a loess sequence in the Yanqing-Huailai-Zhuolu Basin northwest of Beijing also revealed a similar abrupt variation in grain size at approximately $250 \mathrm{ka}$; this variation is regarded as the expansion of the desert boundary over northern China near the Beijing region, such as Hunshandake Sandy Land (Xiong et al., 1999). The Mu-Us Desert and Hunshandake Sandy Land are located in semi-arid regions of North China. Their expansions imply an increasing dry climate in the north-center region of China and the continuous enlargement of Chinese semi-arid regions. These two extreme events at $750-720 \mathrm{ka}$ and $270-250 \mathrm{ka}$ in our study correspond to the expansion of the desert regions in western China and northern China, which are regarded as a twoperiod development of aridification and cooling in the Asian interior (Xiong et al., 1999; Ding et al., 2005).

The results of earlier studies suggest that the uplift of the Himalayan-Tibetan Plateau and the ongoing global cooling and expansion of the Arctic ice-sheet were the two main driving forces of aridification and cooling in the Asian interior (Rea et al., 1998; An et al., 2001; Guo et al., 2002, 2004; Deng et al., 2006; Fan et al., 2006). The latest strong uplift of the Tibetan Plateau and adjacent mountains, which occurred at the end of the Early Pleistocene (0.9-0.8 Ma) (Li, 1999; Ge et al., 2004, 2006), would have blocked the moisture airflow from the southwest to the Asian interior. The Tibetan plateau uplift strengthened the winter monsoon, resulting in the first development of aridification and cooling in the mid-latitude to high-latitude regions of the Asian interior and greatly increasing the atmospheric dust loading since the Middle Pleistocene. The marine oxygen isotope records show the development of a global ice-sheet related to the mid-Pleistocene transition (MPT) from obliquity- to eccentricity-forced climate variations (Shackleton et al., 1990; Park and Maasch, 1993; Paillard, 1998). Wavelet analysis of a stacked magnetic susceptibility record from the loess sequence indicates that the onset of 100-kyr cyclicity was synchronous with the increase of global ice volume at approximately $680 \mathrm{ka}$ (Heslop et al., 2002). A large northern Siberian ice sheet formed and largely extended to the shelf break at approximately $700 \mathrm{ka}$, which directly reveals the expansion of Arctic ice-sheet and the contemporaneous significant cooling (Spielhagen et al., 1997). The expansion of the Arctic ice-sheet intensified the winter monsoon and prevented the high-latitude ocean from providing more moisture to the continental interior, which reinforced the aridification process in the Asian mainland. Therefore, both the uplift of the Himalayan-Tibetan Plateau 


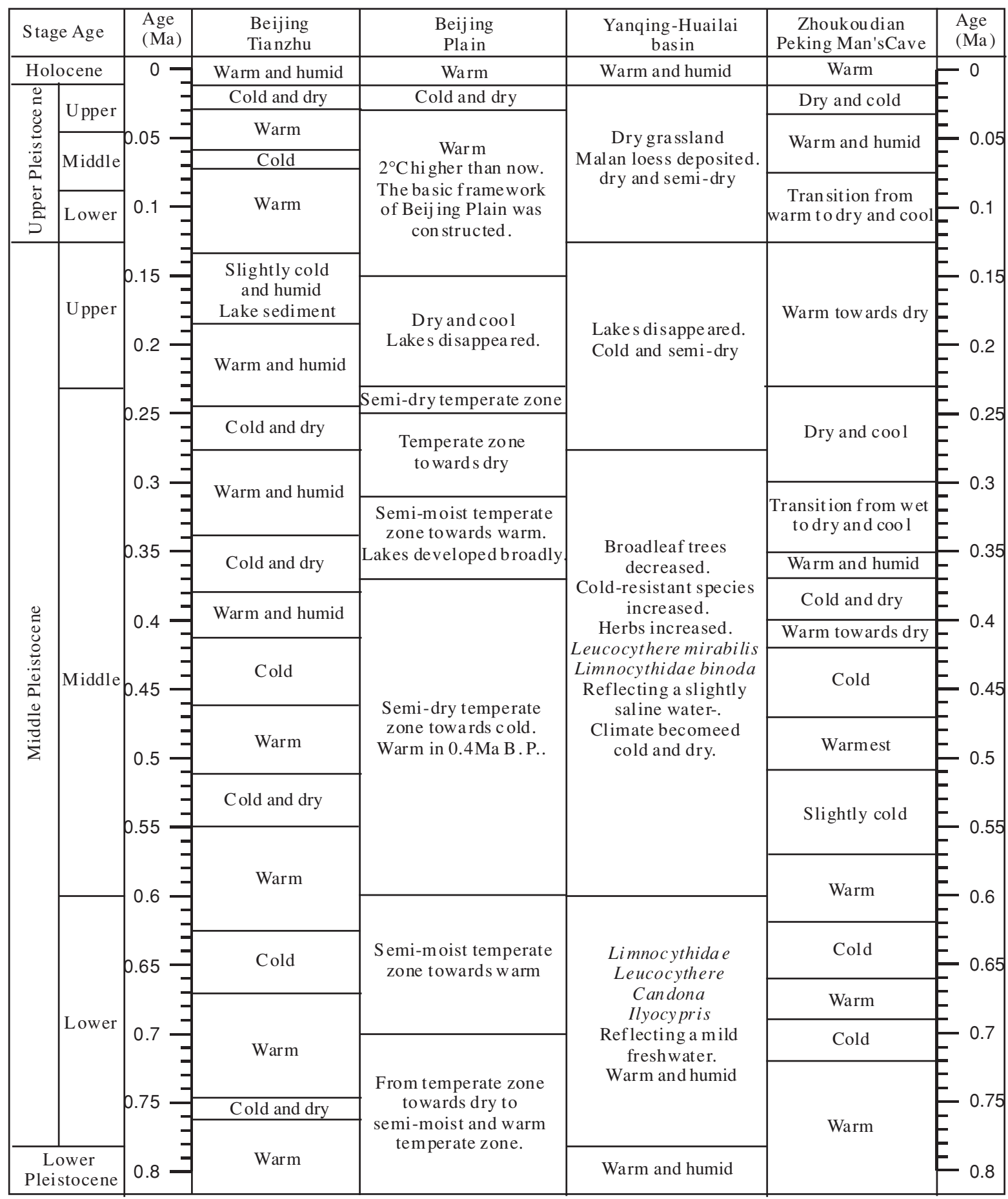

Fig. 10. Comparison with other paleoclimatic records in the Beijing Plain, Yanqing Basin (Li, 1994), Zhoukoudian (Zhou et al., 2000), and Tianzhu borehole. Locations of sites are shown in Fig. 1.

and the expansion of Arctic ice-sheet can be used to interpret the development of aridification and cooling in the Asian interior, especially the extreme event at 750-720 ka recorded in the Tianzhu borehole. However, little evidence on the uplift of the Himalayan-Tibetan Plateau and expansion of Arctic ice-sheet in the period 270-250 ka is available. Consequently, this explanation of the development of aridification and cooling in the Asian interior at 270-250 ka is uncertain and requires further study.

\section{Conclusion}

An almost 186.3-m-thick quasi-continuous sequence of fluvial sediments in the Beijing Plain has been selected for environmental magnetic study. Magnetostratigraphy analysis revealed that the sediment sequences span the last $800 \mathrm{ka}$. A comparison of pollen data and magnetic susceptibility suggests that magnetic susceptibility is a reliable proxy for climate changes, with a high magnetic susceptibility value reflecting warm climate conditions and a low magnetic susceptibility value indicating cold periods. By comparing magnetic susceptibility records and lithol- 
ogy with the ODP $677 \delta^{18} \mathrm{O}$ proxy, we demonstrate that sediments in the interglacial periods were predominated by coarse grain-size sands and silts with a relatively high magnetic susceptibility. In contrast, in the glacial periods, fine grain-size silty clay was deposited, and the values of magnetic susceptibility were relatively low. Therefore, we conclude that climate change was the main factor in controlling the fluvial sedimentary cycles in the study area. The sedimentary model in the subsidence plain shows that the climate controls lithology and its magnetic susceptibility chiefly through changing fluvial discharge and transport capacity, both of which were mainly dominated by precipitation. Our results indicate that the relatively arid environment in the Beijing Plain since the Middle Pleistocene also coincides with climate records in the Yanqin basin and Zhoukoudian cave in the Beijing area. The Tianzhu fluvial sequence records two extreme events at 750-720 ka and 270-250 ka, corresponding to two-episodic development of aridification and cooling in the Asian interior. The uplift of the Himalayan-Tibetan Plateau and the expansion of Arctic ice-sheet may be the main driving factors that controlled the development of aridification and cooling in the Asian interior and the extreme event at 750-720 ka.

Acknowledgments. This work was supported by the Chinese Ministry of Education (20070284030) and the China Geological Survey (200413000035). We thank Drs. Zhiming Sun and Junling Pei for help during the field sampling. We are grateful to Prof. Akira Hayashida and an anonymous reviewer for their insightful comments and suggestions to improve the manuscript. We are grateful for the help of Dr. Yan Wang in the pollen analysis. We especially thank Prof. Qiang Wang for useful discussions.

\section{References}

An, Z. S., J. E. Kutzbach, W. L. Prell, and S. C. Porter, Evolution of Asian monsoons and phased uplift of the Himalaya-Tibetan Plateau since Late Miocene times, Nature, 411, 62-66, 2001.

Autin, W. J. and F. B. Evens, Magnetic susceptibility analysis of Lower Mississippi Valley (LVM) sediments, Proceedings of the Seventh International Conference on Fluvial Sedimentology, Lincoln, Nebraska 50, Abstracts, 2001.

Begét, J. E., D. B. Stone, and D. B. Hawkins, Paleoclimatic forcing of magnetic susceptibility variations in Alaskan loess during the late Quaternary, Geology, 18, 40-43, 1990.

Beijing Geology and Mineral Bureau, Regional Geology of Beijing Municipality, pp. 213-259, Geological Press, Beijing, 1991.

Bloemendal, J., X. M. Liu, and T. C. Rolph, Correlation of the magnetic susceptibility stratigraphy of Chinese loess and the marine oxygen isotope record: chronological and palaeoclimatic implications, Earth Planet. Sci. Lett., 131, 371-380, 1995.

Boës, X., N. Piotrowska, and N. Fagel, High-resolution diatom/clay record in Lake Baikal from grey scale, and magnetic susceptibility over Holocene and Termination I, Glob. Planet. Change, 46, 299-313, 2005.

Brachfeld, S. A. and S. K. Banerjee, Rock-magnetic carriers of centuryscale susceptibility cycles in glacial-marine sediments from the Palmer Deep, Antarctic Peninsula, Earth Planet. Sci. Lett., 176, 443-455, 2000.

Brachfeld, S. A., S. K. Banerjee, Y. Guyodo, and G. D. Acton, A 13200 year history of century to millennial-scale paleoenvironmental change magnetically recorded in the Palmer Deep, western Antarctic Peninsula, Earth Planet. Sci. Lett., 194, 311-326, 2002.

Chen, J., Z. S. An, L. W. Liu, J. F. Ji, J. D. Yang, and Y. Chen, Variations in chemical compositions of the eolian dust in Chinese Loess Plateau over the past $2.5 \mathrm{Ma}$ and chemical weathering in the Asian inland, Sci. China Ser. D, 44, 402-413, 2001.

Chen, Z. B., J. J. Zhang, Y. G. Li, and Z. Liu, Geology of Beijing, in Geological atlas of China, edited by L. F. Ma, pp. 113-118, Geological Press, Beijing, 2002.

Dekkers, M. J., Environmental magnetism: an introduction, Geol. Mijn- bouw, 76, 163-182, 1997.

Deng, C. L., J. Shaw, Q. S. Liu, Y. X. Pan, and R. X. Zhu, Mineral magnetic variation of the Jinbian loess/paleosol sequence in the northern Loess Plateau of China: implications for Quaternary development of Asian aridification and cooling, Earth Planet. Sci. Lett., 241, 248-259, 2006.

Ding, Z. L., E. Derbyshire, S. L. Yang, J. M. Sun, and T. S. Liu, Stepwise expansion of desert environment across northern China in the past 3.5 Ma and implications for monsoon evolution, Earth Planet. Sci. Lett., 237, 45-55, 2005.

Einsele, G., W. Richen, and A. Seilacher, Cycles and events in stratigraphybasic concepts and terms, in Cycles and Events in Stratigraphy, edited by G. Einsele, W. Ricken, and A. Seilacher, pp. 1-19, Springer, Berlin, 1991.

El-Moslinmany, A., The ecological significance of common nonarboreal pollen: example from dryland of the Middle East, Rev. Palaeobot. Palynol., 64, 343-350, 1990.

Evans, M. E., F. Heller, J. Bloemendal, and N. Thouveny, Natural magnetic archives of past global change, Surv. Geophys., 18, 183-196, 1997.

Fan, M. J., C. H. Song, D. L. Dettman, X. M. Fang, and X. H. Xu, Intensification of the Asian winter monsoon after 7.4 Ma: Grain-size evidence from the Linxia Basin, northeastern Tibetan Plateau, 13.1 Ma to 4.3 Ma, Earth Planet. Sci. Lett., 248, 186-197, 2006.

Fang, X. M., Y. Ono, H. Fukusawa, B. T. Pan, J. J. Li, D. H. Guan, K. Oi, S. Tsukamoto, M. Torii, and T. Mishima, Asian summer monsoon instability during the past 60,000 years: magnetic susceptibility and pedogenic evidence from the western Chinese Loess Plateau, Earth Planet. Sci. Lett., 168, 219-232, 1999.

Garcin, Y., D. Williamson, M. Taieb, A. Vincens, P. E. Mathé, and A. Majule, Centennial to millennial changes in maar-lake deposition during the last 45,000 years in tropical Southern Africa (Lake Masoko, Tanzania), Palaeogeogr. Palaeoclimatol. Palaeoecol., 239, 334-354, 2006.

Gasse, F., M. Anold, J. C. Fontes, M. Fort, E. Gilbert, A. Huc, L. Bingyan, L. Yuanfang, L. Qing, F. Melieres, E. Van Campo, F. B. Wang, and Q. S. Zhang, A 13000 year climate record from Western Tibet, Nature, 353, 742-745, 1991.

Ge, X. H., S. M. Ren, Y. J. Liu, G. D. Wu, and S. H. Yuan, Last rapid uplift of Qinghai-Xizang Plateau and the Australasian event of meteorites, Quat. Sci., 24(1), 67-73, 2004 (in Chinese).

Ge, X. H., S. M. Ren, L. X. Ma, G. D. Wu, Y. J. Liu, and S. H. Yuan, Multi-stage uplifts of the Qinghai-Tibet plateau and their environmental effects, Earth Sci. Frontiers, 13(6), 118-130, 2006 (in Chinese).

Gu, Z. Y., Z. L. Ding, S. F. Xiong, and T. S. Liu, A seven million geochemical record from Chinese Red Clay and loess-paleosol sequence: weathering and erosion in northwestern China, Quat. Sci., 19, 357-365, 1999 (in Chinese with English abstract).

Guo, Z. T., W. F. Ruddiman, Q. Z. Hao, H. B. Wu, Y. S. Qiao, R. X. Zhu, S. Z. Peng, J. J. Wei, B. Y. Yuan, and T. S. Liu, Onset of Asian desertification by $22 \mathrm{Myr}$ ago inferred from loess deposits in China, Nature, 416, 159-163, 2002.

Guo, Z. T., S. Z. Peng, Q. Z. Hao, P. E. Biscaye, Z. S. An, and T. S. Liu, Late Miocene-Pliocene development of Asian aridification as recorded in the Red-Earth Formation in northern China, Glob. Planet. Change, 41, 135-145, 2004.

Heller, F. and T. S. Liu, Magnetism of Chinese loess deposits, Geophys. J. R. Astron. Soc., 77, 125-141, 1984.

Heller, F. and T. S. Liu, Palaeocliamtic and sedimentary history from magnetic susceptibility of loess in China, Geophys. Res. Lett., 13, 11691172,1986

Heller, F. and M. E. Evans, Loess magnetism, Rev. Geophys., 33, 211-240, 1995.

Heslop, D., C. G. Langereis, and M. J. Dekkers, A new astronomical timescale for the loess deposits of northern China, Earth Planet. Sci. Lett., 184, 125-139, 2000.

Heslop, D., M. J. Dekkers, and C. G. Langereis, Timing and structure of the mid-Pleistocene transition: records from the loess deposits of northern China, Palaeogeogr. Palaeoclimatol. Palaeoecol., 185, 133-143, 2002.

Hinnov, L. A., Earth's orbital parameters and cycle stratigraphy, in $A$ Geologic Time Scale, edited by Granstein, M., J. G. Ogg, and A. G. Smith, Cambridge University Press, Untied Kingdom, 55-62, 2004.

Hovan, S. A., D. K. Rea, N. G. Pisias, and N. J. Shackleton, A direct link between the China loess and marine $\delta^{18} \mathrm{O}$ records: aeolian flux to the North Pacific, Nature, 340, 296-298, 1989.

Huang, X. Z., F. H. Chen, Y. X. Fan, and M. L. Yang, Dry late-glacial and early Holocene climate in arid central Asia indicated by lithological and palynological evidence from Bosten Lake, China, Quat. Int., doi:10.1016/j.quaint.2007.10.002, 2007. 
Jansen, E. and J. Sjoholm, Reconstruction of glaciation over the past $6 \mathrm{Myr}$ from ice-borne deposits in the Norwegian Sea, Nature, 349, 600-603, 1991.

Jia, S. M., Y. Guo, C. Ye, Y. Liu, S. S. Zhao, Y. Luo, H. J. Zhang, Z. Q. Liu, and B. L. Jiao, The early warning system of Beijing ground subsidence monitoring website (one stage): The report on engineering ground subsidence, Hydrogeology and Engineering Geology Team of Beijing, pp. 24-43, 2004.

Kalm, V. E., N. W. Rutter, and C. D. Rokosh, Clay minerals and their paleoenvironmental interpretations in the Baoji loess section, southern Loess Plateau, China, Catena, 27, 49-61, 1996.

Kukla, G., F. Heller, X. M. Liu, T. C. Xu, T. S. Liu, and Z. S. An, Pleistocene climates in China dated by magnetic susceptibility, Geology, 16, 811-814, 1988.

Langereis, C. G., M. J. Dekkers, G. J. de Lange, M. Pateme, and P. J. M. van Santvoort, Magnetostratigrphy and astronomical calibration of the last 1.1 Myr from an eastern Mediterranean piston core and dating of short events in the Brunhes, Geophys. J. Int., 129, 75-94, 1997.

Li, H. Z., The Quaternary Palaeogeographic Study on Beijing Areas, 165 pp., Geology Press, Beijing, 1994.

Li, J. J., Studies of the geomorphological evolution of the Qinghai-Xizang (Tibetan) Plateau and Asian monsoon, Mar. Geol. Quat. Geol., 19(1), 1-11, 1999 (in Chinese).

Li, Y. C., Q. H. Xu, Y. K. Zhao, X. L. Yang, J. L. Xiao, H. Chen, and X. M. Lv, Pollen indication to source plants in the eastern desert of China, Chinese Sci. Bull., 50, 1632-1641, 2005.

Lowrie, W., Identification of ferromagnetic minerals in a rock by coercivity and unblocking temperature properties, Geophys. Res. Lett., 17, 159162, 1990.

Manabe, S. and A. J. Broccoli, Mountains and climates of middle latitudes, Science, 247, 192-195, 1990.

Nádor, A., M. Lantos, Á. Tóth-Makk, and E. Thamó-Bozsó, Milankovichscale multi-proxy records from fluvial sediments of the last $2.6 \mathrm{Ma}$, Pannonian Basin, Hungary, Quat. Sci. Rev., 22, 2157-2175, 2003.

Paillard, D., The timing of Pleistocene glaciations from a simple multiplestate climate model, Nature, 391, 378-381, 1998.

Park, J. and K. A. Maasch, Plio-Pleistocene time evolution of the 100-kyr cycle in marine palaeoclimate records, J. Geophys. Res., 98(B1), 447461, 1993.

Ramstein, G., F. Fluteau, J. Besse, and S. Joussaume, Effect of orogeny, plate motion and land-sea distribution on Eurasian climate change over the past 30 million years, Nature, 286, 788-795, 1997.

Rea, D. K., H. Snoeckx, and L. H. Joseph, Late Cenozoic eolian deposition in the North Pacific: Asian drying, Tibetan uplift, and cooling of the northern hemisphere, Paleoceanography, 13, 215-224, 1998.

Ruddiman, W. F. and J. E. Kutzbach, Forcing of late Cenozoic northern hemisphere climate by plateau uplift in southern Asian and the Ameri- can West, J. Geophys. Res., 94, 18409-18427, 1989.

Shackleton, N. J. and N. G. Pisias, Atmospheric carbon dioxide, orbital forcing, and climate, in The Carbon Cycle and Atmospheric $\mathrm{CO}_{2}: \mathrm{Natu}$ ral Variations Archean to Present, Geophysical Monorgraph Series, vol. 32, edited by E. T. Sundquist and W. S. Broeker, pp. 412-417, 1985.

Shackleton, N. J., A. Berger, and W. R. Peltier, An alternative astronomical calibration of the lower Pleistocene timescale based on ODP Site 677, Trans. R. Soc. Edinb. Earth Sci., 81, 251-261, 1990.

Shackleton, N. J., M. A. Hall, and D. Pate, Pliocene stable isotope stratigraphy of Site 846, in Proceedings of Ocean Drilling Program Scientific Results, Vol. 138, edited by N. G. Pisias, L. A. Janacek, A. PalmerJulson, and T. H. Van Andel, pp. 337-355, 1995.

Shan, Q. S., H. L. Yang, and L. G. Liu, The environmental evolution of Quaternary of Beijing-Tongxian region, Beijing Geol., 4, 1-7, 1994 (in Chinese).

Spielhagen, R. F., G. Bonani, A. Eisenhauer, M. Frank, T. Frederichs, H. Kassens, P. W. Kubik, A. Manini, N. Nørgaard-Pedersen, N. R. Nowaczyk, S. Schäper, R. Stein, J. Thiede, R. Tiedemann, and M. Wahsner, Arctic Ocean evidence for late Quaternary initiation of northern Eurasian ice sheets, Geology, 25(9), 783-786, 1997.

Sun, J. M. and T. S. Liu, Stratigraphic evidence for the uplift of the Tibetan Plateau between $\sim 1.1$ and $\sim 0.9$ Myr ago, Quat. Res., 54, 309-320, 2000.

Van Campo, E. and F. Gasse, Pollen- and diatom-inferred climatic and hydrological changes in Sumxi Co Basin (Western Tibet) since 13,000 yr BP, Quat. Res., 39(3), 300-313, 1993.

Wu, C., Q. H. Xu, Y. H. Ma, X. Q. Zhang, Palaeochannels on the North China Plain: Palaeoriver, Geomorphology, 18, 37-45, 1996a.

Wu, C., Q. H. Xu, X. Q. Zhang, and Y. H. Ma, Palaeochannels on the North China Plain: types and distributions, Geomorphology, 18, 5-14, $1996 \mathrm{~b}$.

Xiong, S. F., Z. L. Ding, and T. S. Liu, Loess deposits in Beijing region since last 1.2 Ma and desert expansion over northern China, Mar. Geol. Quat. Geol., 19(3), 67-73, 1999 (in Chinese).

Xu, Q. H., C. Wu, X. L. Yang, and N. J. Zhang, Palaeochannels on the North China Plain: relationships between their development and tectonics, Geomorphology, 18, 27-35, 1996a.

Xu, Q. H., C. Wu, X. Q. Zhu, and X. L. Yang, Palaeochannels on the North China Plain: stage division and palaeoenvironments, Geomorphology, 18, 15-25, 1996b.

Zhou, C. L., Z. C. Liu, Y. J. Wang, and Q. H. Huang, Climatic cycles investigated by sediment analysis in Peking Man's Cave, Zhoukoudian, China, J. Archaeol. Sci., 27, 101-109, 2000.

L. Shi, Z. Yang (e-mail: yangzy@public3.bta.net.cn), L. Zheng, S. Jia, Y. Tong, S. Zhang, D. Xu, and G. Guo 